This is not only a mortifying fact, but a grave misfortune. It is intensely annoying both to the physician and chemist when it is discovered that a sulustance which has long been prescribed by the one and dispensed by the other has no more value than an equal weight of starch; and it is a misfortune to the whole community when a valuable medicine is thrown into discredit by bungling if not fradulent manufacture.

Fortunately, a very simple experiment enables us to judge whether a given sample of pepsin is up to the standard of quality. It may be conducted as follows:-Boil an egg for an hour, and cut a portion of the white into the thinnest possible slices. Take a two-ounce wide-mouthed bottle and introduce into it $77 \mathrm{grs}$. ( 5 grammes) of the sliced white of egg, $1 \frac{1}{2}$ gr. of pepsin, 4 minims of strong hydrochloric acid, and 420 minims of distilled water. Place the bottle in a water-bath, and keep it for four hours at a temperature of $100^{\circ} \mathrm{F}$. A higher temperature (not exceeding $120^{\circ} \mathrm{F}$.) causes more rapid digestion; but it is, perhaps, better to work at about the temperature of the stomach. At the end of the experiment all the albumen should bave been dissolved, nothing remaining but minute quantities of fibrous or membranous matters.

The above proportions are those used by Prof. Tuson in some experiments to which we shall afterwards refer, and that the test is not unduly severe is proved by the fact that with one of the samples he examined, half the quantity of pepsin here prescribed ( 0.05 gramme, equal to 0.75 grain) was found sufficient to dissolve the albumen. With samples that contain much starch, double the above quantities of acid and water must be used. The residue may be thrown upon a muslin filter and examined. Unaltered albumen will be clearly visible, even if much starch, \&c., are present. In many cases it is possible to form a rough measure of the comparative value of different samples by collecting the residual albumen (if there be any), placing it on filter-paper for a short time to drain, and weighing it.

Another and in some respects better mode of measuring the action of pepsin has recently been proposed by Gruenhagen (Pflïger's Archiv, v. 203). Recent and moist blood fibrin is soaked in 0.2 per cent. hydrochloric until a stiff jelly is formed. The jelly is then placed on a filter, and allowed to stand till no more drops fall. A few drops of a solution of the pepsin are then added. In about two minutes the fibrin begins to dissolve and drops of peptone to fall. The rapidity with which these drops fall, or, as afterwards suggested by von Wittich (op cit., v. 435), the amount which falls in a given time, is taken as a measure of the activity of the pepsin. The experiment might be better made, as Gruenhagen suggests, if the bath were maintained at a given temperature - say $100^{\circ}$ or $120^{\circ} \mathrm{F}$. by means of a hot-water funnel. There would, however, be some difficulty in keeping the temperature quite constant, and this condition is essential, as the rate of digestion increases steadily up to $120^{\circ} \mathrm{F}$, or even a little higher.

The researches of Professor Tuson, to which we have already referred, were published in THE LANCET of August 13th, 1870. They had for their object the comparison of the real value of some of the chief kinds of pepsin then in the market, and they were evidently conducted with great care. Ten different samples, prepared by six different makers, were examined, and the results tabulated. The experiments, all of which were performed in duplicate, were divided into two series. In one, white of egr, in the other finely minced lean of rump-steak was employed. In every experiment 5 grammes ( 77 grains) of the albumen or fibrin was mixed with either 25 or 50 c.c. ( 424 or 848 minims) of one per cent. hydrochloric acid. Quantities of pepsin which varied from 0.05 to 5.0 grammes $(0.72$ to 72 grains) were added, and the whole digested at $100^{\circ} \mathrm{F}$. for four hours. The results are given in tables which are well worth examination. The pepsin prepared by four out of the six makers was found to have no digestive power whatever. Of the remaining two kinds, one was almost exactly ten times as good as the other. Nearly 300 experiments were made in all, and the pre-eminent value of the one make of pepsin over all the others examined was incontestibly shown.

Another series of experiments on the comparative value of the pepsins of commerce has recently appeared in "The Practitioner" (June and August, 1872.)

These experiments were made by a process somewhat similar, but decidedly inferior, to that employed by Prof. Tuson, whose previous labours are not referred to in the articles. Small cubes of egg-albumen were introdticed into a mixture of 100 c.c. of water, $0 \cdot 4$ c.c. of strong hydrochloric acid, and 1 gramme of the pepsin to be examined. The mixture was maintained for three hours and a half at a temperature of $90^{\circ}-95^{\circ}$ Fahr., and the quantity of albumen dissolved was then determined by some method not described. Examined in this way all the samples tested were pronounced to be nearly worthless, a slight advantage being, however, assigned to one of them. We confess we do not attach much importance to these experiments. The temperature was too low, and the time too short for satisfactory results. Moreover cubes are much less easily digested than thin slices, and we doubt very much whether the measurements of dissolved albumen are to be trusted.

A more important contribution to our knowledge of pepsin is to be found in the interesting experiments of Mr. Scheffer. We should be glad to hear of an independent verification of Mr. Scheffer's results, because they promise to yield us not only a good and simple mode of preparing pepsin, but also a satisfactory means of assay. His most important observation is that pepsin may be precipitated from its slightly acid solution by the addition of an equal volume of a saturated solution of common salt He also finds that true pepsin and bismuth cannot exist in the same solution, and that the solutions sold under the joint names are therefore worthless, as far as pepsin is concerned.

Upon one point there would still appear to be some doubt. Mr. Scheffer asserts, and his experiments seem to prove, that the activity of pepsin is destroyed by alcohol, even when diluted with an equal bulk of water, and is materially diminished by smaller quantities of alcohol. This would of course put an end to the use of pepsin wine. But, on the other hand, von Wittich, in the paper already quoted, asserts that pepsin may be extracted from gastric mucous membrane (the pyloric portion being rejected) after it has been steeped in alcohol, and even from the precipitate produced in glycerin extract of fresh mucous membrane by the addition of alcohol.

Further experiments on the whole subject, however, are demanded.

\section{OPHTHALMIA IN SCHOOLS.}

\section{To the Editor of THE LANCET.}

SiR,-If it be true that crowding in dormitories is the chief source of contagious ophthalmia, will you kindly explain how it is that Forest-gate District School, with many dormitories affording less than 200 cubic feet per child, and the entire average much below 300 , is perfectly free from contagious ophthalmia, whilst the North Surrey School, with 360 cubic feet per child, is full of that disease?

Ten years ago, when I became connected with Forestgate school, there were little over 300 children, nearly all affected; now there are 340 in the same space, and no disease. How is this?

I am medical officer to the West Ham Union Workhouse, having about 300 children; cubic space of dormitories below 200 cubic feet each; and ophthalmia unknown. How is this?

I am, Sir, yours faithfully,

Thomas J. Vallance, M.D., F.R.C.S. Exam.

Stratford, E., April 16th, 1873.

\section{To the Editor of Try LaNCET.}

SIR,-In an editorial paragraph in this week's LANCET my name is mentioned in connexion with a letter to the editor of The Times, on the subject of ophthalmia in schools. I quite concur in the tenor of the letter in question, especially as to the desirability of more efficient medical inspection of such schools; but as some one else wrote the letter, I cannot claim any merit from the suggestion.

I am, Sir, your obedient servant,

W. SPENCER WATSON.

Henrietta-street, Cavendish-square, April 16th, 1873. 